\title{
Cefoperazone sodium preparation behavior after intramammary administration in healthy and infected cows
}

\author{
P. Cagnardi, ${ }^{11}$ R. Villa, ${ }^{*}$ M. Gallo, ${ }^{*}$ C. Locatelli, S. Carli, ${ }^{*}$ P. Moroni, $† \ddagger$ and A. Zonca* \\ *Università degli Studi di Milano, Department of Veterinary Sciences and Technologies for Food Safety, 20133 Milan, Italy \\ †Università degli Studi di Milano, Department of Veterinary Pathology, Hygiene and Public Health, 20133 Milan, Italy \\ ‡Quality Milk Production Services, Cornell University, 22 Thornwood Drive, Ithaca, NY 14850
}

\section{ABSTRACT}

Selection of the antimicrobial agent and maintenance of adequate drug concentrations at the site of infection are the most relevant problems in mastitis antibiotic therapy. Intramammary drug efficacy can be maximized by keeping drug concentrations at the site of infection above the minimum inhibitory concentration (MIC) as long as possible; the most important pharmacokinetic and pharmacodynamic (PK/PD) measure for efficacy evaluation is time during which drug concentrations exceed the MIC $(t>$ MIC). To evaluate this measure, the PK profile of cefoperazone (CFP) after single intramammary administration in healthy and subclinical infected Staphylococcus aureus cows and the MIC of Staph. aureus field strains were assessed. In addition, the degree of drug passage from udder to bloodstream was investigated by measuring systemic drug absorption in healthy and infected animals. Cefoperazone concentrations were quantified by HPLC in quarter milk samples and blood serum samples. Systemic drug absorption was negligible in healthy animals $(0.020 \pm 0.006 \mu \mathrm{g} /$ $\mathrm{mL}$ serum at $4 \mathrm{~h}$ ), whereas it was higher in infected animals $(0.102 \pm 0.079 \mu \mathrm{g} / \mathrm{mL}$ at $4 \mathrm{~h}$ and $0.025 \mu \mathrm{g} / \mathrm{mL}$ at $24 \mathrm{~h}$ ), probably due to the damage of epithelial cell junctions caused by subclinical infections. The $\mathrm{MIC}_{90}$ value for CFP in Staph. aureus field strains $(\mathrm{n}=24)$ was $0.64 \mu \mathrm{g} / \mathrm{mL}$. The PK/PD evaluation, determined by $t>\mathrm{MIC}$, showed a longer persistence of CFP in infected quarters than in healthy ones (mean residence time was $8.37 \pm 1.51$ vs. $11.42 \pm 5.74 \mathrm{~h}$ in September and $2.07 \pm 0.43$ vs. $3.31 \pm 0.91 \mathrm{~h}$ in October), with a $t>\mathrm{MIC}$ of $45 \pm 6 \mathrm{~h}$ for infected quarters versus $38 \pm$ $5 \mathrm{~h}$ for healthy quarters different only in October. This could mean a prolonged time in which microorganisms are exposed to drug activity and thus, a greater efficacy of the drug.

Received April 27, 2010

Accepted June 1, 2010.

${ }^{1}$ Corresponding author: petra.cagnardi@unimi.it
Key words: intramammary administration, cefoperazone sodium preparation, lactating cow, minimum inhibitory concentration

\section{INTRODUCTION}

Bovine mastitis is the most frequent reason for antimicrobial drug use in dairy farms. Although numerous antimicrobial agents are available to treat mastitis, the cure rate is unsatisfactory, particularly for treatment during lactation. The success of antimicrobial therapy is influenced by various factors, such as the location and susceptibility of microorganisms, the animal's health, and the kinetics of the administered drug (Barragry, 1994b).

Intramammary administration (IMM) is a useful tool for IMI treatment and offers the achievement of high drug concentrations at the site of infection without systemic absorption and related tissue residues, but IMI leads to vascular permeability changes that often enhance systemic absorption. Opinions about longer drug elimination in glands with IMI are conflicting: some evidence suggests that cows with mastitis have a slower elimination of IMM antibiotics, probably because of the disruption of epithelial cell junctions and the consequent deep tissue penetration of drugs (Gehring and Smith, 2006).

Intramammary infection sustained by Staph. aureus may result in clinical or subclinical mastitis. Treatments of subclinical mastitis during lactation are often unsuccessful due to the particular characteristics of the microorganism; that is, its ability to escape from drug activity by penetration and survival in phagocytes (Barkema et al., 2006). Most of the drugs currently available as IMM products act as time-dependent antimicrobial agents. Their efficacy is maximized by maintaining drug concentrations above the MIC at the site of infection as long as possible (Wagner and Erskine, 2006). The best pharmacokinetic and pharmacodynamic $(\mathbf{P K} / \mathbf{P D})$ measure to describe time-dependent drug efficacy is the time during which the drug concentration exceeds the MIC $(t>$ MIC; McKellar et al., 2004; 
Wagner and Erskine, 2006). Pharmacokinetic data on antimicrobial agents used to treat IMI are normally obtained in healthy animals, but differences in PK between healthy and infected cows could occur.

Cefoperazone (CFP) is a third-generation cephalosporin that can be used for IMM due to its broad spectrum of activity (both gram-negative and grampositive bacteria), nonirritant properties, and high persistence in treated quarters after single administration (Barragry, 1994a; Prescott, 2006).

The purpose was to evaluate the PK profile of CFP after single IMM administration in healthy and infected (Staph. aureus) lactating cows. The systemic drug absorption was investigated to evaluate its possible increase due to changes in vascular permeability caused by IMI (Gehring and Smith, 2006). Moreover, the dosage regimen of drug to optimize MIC was determined and the $t>$ MIC was calculated.

\section{MATERIALS AND METHODS}

\section{Animal Selection}

The animals were kindly provided by a dairy commercial farm in northern Italy, where 140 milking cows were tested for Staph. aureus and $40 \%$ were infected. Among the animals tested, 12 lactating cows (Italian Frisona), 650 to $750 \mathrm{~kg}$ of BW $(682 \pm 49 \mathrm{~kg})$ in first or second lactation were selected. All cows were provided with water ad libitum and a TMR drug-free diet. At the onset of the study, the animals were between 60 and 180 DIM $(131 \pm 38 \mathrm{~d})$. The cows were milked twice daily in an $8+8$ herringbone milking parlor. Milk production was $34.6 \pm 9.1 \mathrm{~L} / \mathrm{d}$ (range 26 to $55 \mathrm{~L} / \mathrm{d}$ ).

\section{Preliminary Bacteriology}

Forty-three lactating cows were sampled in a screening phase for $3 \mathrm{wk}$ to define their infection status for Staph. aureus. Ten microliters of milk sample from each quarter were plated onto blood agar (Oxoid, Basingstoke, UK) supplemented with 5\% defibrinated sheep blood (Microbiol Diagnostici, Cagliari, Italy). The plates were incubated aerobically at $37^{\circ} \mathrm{C}$ for $24 \mathrm{~h}$. Putative suspected colonies were subcultured and their identification as Staph. aureus was confirmed by coagulase test and ID32Staph (Bio-Merieux, Marcy-l'Etoile, France). Infection status was defined according to the procedures recommended by National Mastitis Council (1999), and SCC was determined for each sample on an automated fluorescent microscopic somatic cell counter (Bentley Somacount, Bentley Instruments, Chaska, $\mathrm{MN})$. According to the presence or absence of staphylococcal infection in quarters, cows were divided into healthy (group H) and infected (group I) groups. The persistence of infectious or noninfectious conditions was monitored during the following period by subsequent samplings in selected cows belonging to the groups.

\section{MIC Determination}

Twenty-four isolates from infected quarters $(\mathrm{n}=18)$ and from other animals belonging to the same farm but not included in the study $(\mathrm{n}=6)$ were tested for antimicrobial susceptibility to CFP by the determination of MIC according to the microdilution broth method as recommended by NCCLS (2002). Cefoperazone sodium salt (purity grade 90.4\%, Sigma-Aldrich, Milan, Italy) was dissolved in suitable solvent and then diluted in sterile distilled water. Isolates were prepared by diluting an overnight Mueller-Hinton broth culture in buffered saline solution to a density of 0.5 on the McFarland turbidity scale. For each isolate, the MIC was defined as the lowest concentration of CFP at which bacterial growth was completely inhibited. A reference strain of Staph. aureus (ATCC 29213; American Type Culture Collection, Manassas, VA) was inoculated as a control.

\section{Treatment and Sampling}

After accurate milking and teat disinfection, each quarter of each cow was administered with $300 \mathrm{mg}$ IMM of CFP sodium preparation (Starmast, Gellini, Milan, Italy). All quarters, infected or not infected, were administered CFP to reach a high dose $(1,200 \mathrm{mg}$ of CFP per animal). The treatments were carried out in 2 months: September and October, hereafter identified as initial and late periods of treatment.

Milk samples were collected separately from individual teats before (t0) and after drug administration $(0.5,1,2,4,8$, and $12 \mathrm{~h})$. Then, after complete milking, further samples were collected every $12 \mathrm{~h}$ until the 10th milking. Differences in milk pH due to drug administration or infection status of the udder were recorded in milk samples collected at t 0 and $0.5 \mathrm{~h}$.

Blood samples were collected from the jugular vein at t0 and after drug administration $(0.5,1,2,4,8,12$, 24,36 , and $48 \mathrm{~h}$ ) and were subsequently centrifuged to obtain serum. All samples were stored at $-20^{\circ} \mathrm{C}$ pending assay.

\section{Sample Extraction and HPLC Analyses}

Cefoperazone was extracted from $2 \mathrm{~mL}$ of milk or serum according to the method described by Sørensen and Snor (2000). Then, $7 \mathrm{~mL}$ of acetonitrile was added to all samples, centrifuged $(1,500 \times g$ for $10 \mathrm{~min})$, and purified by solid-phase extraction using cartridges (Wa- 
ters tC18, $500 \mathrm{mg}$, Waters S.p.A., Milan, Italy). The dry residue was reconstituted with $1 \mathrm{~mL}$ of water, and $100 \mu \mathrm{L}$ was injected in the HPLC system. Cefoperazone concentrations in milk and serum samples were separated by a Nova-Pak Phenyl column $(150 \times 3.9,4 \mu \mathrm{m})$ with guard column (Waters S.p.A.). The HPLC system (Series 200, Perkin Elmer, Milan, Italy) consisted of a binary pump, autosampler, peltier column oven set at $20^{\circ} \mathrm{C}$, and UV-visible detector set at a wavelength of $270 \mathrm{~nm}$. The mobile phase was (A) octanesulfonic acid solution $(0.005 \mathrm{M}, \mathrm{pH} 2.52)$ and acetonitrile (10\%) and (B) a mixture of acetonitrile-methanol and octanesulfonic acid solution to $1,000 \mathrm{~mL}(\mathrm{~A}: \mathrm{B}=65: 35$ ratio) with a flow rate of $1 \mathrm{~mL} / \mathrm{min}$ (Sørensen and Snor, 2000).

\section{Intralaboratory Validation of Analytical Method}

The calibration curves were made in blank bovine milk and serum diluting the original CFP stock solution $(1 \mathrm{mg} / \mathrm{mL})$ to obtain CFP final concentrations ranging from 0.025 to $25 \mu \mathrm{g} / \mathrm{mL}$. The CFP retention time of milk and serum was $10.6 \pm 0.2 \mathrm{~min}$. The HPLC method was validated for both matrices and was specific, linear (range 0.025 to $25 \mu \mathrm{g} / \mathrm{mL}$ for both matrices), precise ( 11.7 to $3.66 \%$ in milk and 2 to $6 \%$ in serum), and accurate (between $+1.2 \%$ and $-15.5 \%$ in milk and between $+17.1 \%$ and $-0.66 \%$ in serum). The lower and upper limits of quantification (LOQ) were $0.01 \mu \mathrm{g} / \mathrm{mL}$ and $25 \mu \mathrm{g} / \mathrm{mL}$, respectively, for milk and serum. Samples with concentrations greater than the upper LOQ were quantified after dilution. The limit of detection was $0.002 \mu \mathrm{g} / \mathrm{mL}$ for both matrices. Mean recovery was 78 and $70 \%$ for milk and serum, respectively.

\section{Pharmacokinetic Analysis}

A noncompartmental analysis was carried out on milk and serum drug concentrations using the WinNonLin 5.2.1 software (Pharsight Corporation, Mountain View, CA). Mean residence time (MRT) was determined from the following equation (Gibaldi and Perrier, 1982):

$$
\mathrm{MRT}=\mathrm{AUMC} / \mathrm{AUC},
$$

where AUMC is area under the moment curve and AUC is area under serum concentration-time curve.

\section{Statistical Analysis}

Differences were investigated between healthy and infected animals and between initial and late periods of treatment using unpaired $t$-test with Welch correction (variances unequal) on elimination half-life $\left(\mathbf{t}_{1 / 2 \lambda z}\right)$, maximum concentration $\left(\mathbf{C}_{\max }\right), \mathrm{AUC}_{\text {last }}$, and $\mathrm{MRT}_{\text {last }}$, where last indicates value calculated from 0 to last time point (InStat 3.0 GraphPad, La Jolla, CA). The same test was performed to investigate differences in $\mathrm{pH}$ values before and after treatment, whereas ANOVA was performed to evaluate differences among groups of quarters. In both tests, differences with $P<0.05$ were considered significant.

\section{RESULTS}

The animal phase was conducted on 12 lactating cows divided into 6 healthy (group H) and in 6 Staph. aureus infected (group I) cows. To simplify drug administration and sample collection, the 2 groups were additionally divided into 2 different periods of treatment, with 3 animals from group $\mathrm{H}$ and 3 from group I. Unfortunately, results from the 2 different periods of treatment were not comparable; consequently, results are reported and considered separately.

Because drug quantification was carried out in samples from single quarters, results from group $\mathrm{H}$ were identified as healthy quarters $(\mathbf{H Q}, \mathrm{n}=23)$, whereas results from group I were divided into infected quarters $(\mathbf{I Q}, \mathrm{n}=18)$ and suspected quarters $(\mathbf{S Q}$, i.e., healthy quarters of infected animals, $\mathrm{n}=5$ ).

In the initial period, CFP was detected in milk for 84 $\mathrm{h}$ in most of the IQ and for $72 \mathrm{~h}$ in HQ and SQ; in these last 2 groups, only 1 quarter per group showed quantifiable concentrations after $84 \mathrm{~h}$. In the late period in most quarters CFP was detected for 48 and $60 \mathrm{~h}$ after treatment, but only in $1 \mathrm{SQ}, 2 \mathrm{IQ}$, and $3 \mathrm{HQ}$ was it quantifiable for $72 \mathrm{~h}$.

Mean milk PK measures are in Table 1. Mean milk $\mathrm{pH}$ values measured at $\mathrm{t} 0$ and $0.5 \mathrm{~h}$ after treatment are in Table 2. Serum concentrations were quantifiable in only a few animals and mean results are in Table 3. Concentrations were always low and near the lower LOQ $(0.01 \mu \mathrm{g} / \mathrm{mL})$. In healthy and infected subjects, CFP was detectable for 4 and $24 \mathrm{~h}$, respectively. The lack of evident differences in the low drug concentrations did not allow a kinetic analysis of serum data.

The drug inhibitory concentrations toward Staph. aureus field strains $(\mathrm{n}=24)$ ranged from 0.48 to 0.97 $\mu \mathrm{g} / \mathrm{mL}$. The calculated $\mathrm{MIC}_{90}$ was $0.64 \mu \mathrm{g} / \mathrm{mL}$. The $t$ $>$ MIC values (Table 1) were calculated in milk and resulted in the initial period of $58 \pm 7 \mathrm{~h}$ and $65 \pm 11$ $\mathrm{h}$ in HQ and IQ $(P>0.05)$, respectively; whereas, in the late period $t>\mathrm{MIC}$ were $38 \pm 5 \mathrm{~h}$ and $45 \pm 6 \mathrm{~h}$ in HQ and IQ $(P<0.05)$, respectively. The $t>$ MIC of SQ were $60 \pm 17$ and $42 \pm 8 \mathrm{~h}$ in the initial and late periods $(P>0.05)$, respectively.

\section{DISCUSSION}

Pharmacokinetic studies are usually carried out in healthy animals, whereas in this study, cows with Staph. 
Table 1. Mean ( \pm SD) milk pharmacokinetic measures after intramammary administration of cefoperazone in healthy (HQ), infected (IQ) and suspected quarters (SQ) in the initial and late period of treatment

\begin{tabular}{|c|c|c|c|c|c|c|}
\hline \multirow[b]{2}{*}{ Measure $^{1,2}$} & \multicolumn{2}{|c|}{ HQ } & \multicolumn{2}{|l|}{ IQ } & \multicolumn{2}{|c|}{ SQ } \\
\hline & Mean & $\pm \mathrm{SD}$ & Mean & $\pm \mathrm{SD}$ & Mean & $\pm \mathrm{SD}$ \\
\hline $\mathrm{t}_{1 / 2 \lambda \mathrm{z}}(\mathrm{h})$ & $6.73^{*(\mathrm{IQ})}$ & 2.91 & $4.25^{*(\mathrm{HQ})}$ & 0.84 & 4.57 & 1.85 \\
\hline $\mathrm{T}_{\max }(\mathrm{h})$ & 0.67 & 0.44 & 0.5 & 0 & 0.5 & 0 \\
\hline $\mathrm{C}_{\max }(\mu \mathrm{g} / \mathrm{mL})$ & $445.6 \S$ & 287.1 & $310.0 \S$ & 180.8 & 434.0 & 294.6 \\
\hline $\mathrm{AUC}_{\text {last }}(\mathrm{h} . \mu \mathrm{g} / \mathrm{mL})$ & $3,182.9 \S$ & $1,612.8$ & $2,069.8 \S$ & 791.3 & $2,947.1$ & $1,318.4$ \\
\hline$t>\mathrm{MIC}(\mathrm{h})$ & 58 & 7 & $65 \S$ & 11 & 60 & 17 \\
\hline Late period & \multicolumn{2}{|c|}{$(\mathrm{n}=11)$} & \multicolumn{2}{|c|}{$(\mathrm{n}=10)$} & \multicolumn{2}{|c|}{$(\mathrm{n}=2)$} \\
\hline $\mathrm{t}_{1 / 2 \lambda z}(\mathrm{~h})$ & 6.89 & 3.49 & 4.77 & 2.29 & 3.82 & 1.31 \\
\hline $\mathrm{T}_{\max }(\mathrm{h})$ & 2.0 & 0 & 0.5 & 0 & 0.5 & 0 \\
\hline $\mathrm{C}_{\max }(\mu \mathrm{g} / \mathrm{mL})$ & $2,522.9 \S^{2} *(\mathrm{SQ})$ & 899.9 & $2,779.4 \S^{*} *(\mathrm{SQ})$ & 812.7 & $824.9^{*(\mathrm{IQ} ; \mathrm{HQ})}$ & 9.8 \\
\hline $\mathrm{AUC}_{\text {last }}(\mathrm{h} . \mu \mathrm{g} / \mathrm{mL})$ & $18,173.7 \S, *(\mathrm{IQ} ; \mathrm{SQ})$ & $6,403.5$ & $10,180.2 \S *(\mathrm{SQ} ; \mathrm{HQ})$ & $4,105.2$ & $4,243.3^{*(\mathrm{IQ} ; \mathrm{HQ})}$ & 642.5 \\
\hline
\end{tabular}

${ }^{1} \mathrm{t}_{1 / 2 \lambda \mathrm{z}}=$ elimination half-time; $\mathrm{T}_{\max }=$ observed time for maximum concentration $\left(\mathrm{C}_{\max }\right) ; \mathrm{AUC}_{\text {last }}=$ area under milk concentration-time curve; $\mathrm{AUMC}_{\text {last }}=$ area under the moment curve; $\mathrm{MRT}_{\text {last }}=$ mean residence time; $t>\mathrm{MIC}=$ time during which concentration is above $\mathrm{MIC}$.

${ }^{2}$ Initial and late periods $=$ first (September) and second (October) periods of treatment.

${ }^{*} P<0.05$, difference statistically significant between quarters in the same period (letters in parentheses show groups).

$\S P<0.05$, difference statistically significant between quarters of the same group in different periods.

aureus subclinical infections were selected because the aim was to investigate possible differences in drug behavior in animals in which the mammary environment was modified by recurrent Staph. aureus infections. The subclinical stage was preferred to an acute IMI stage, because serious gland modifications could heavily affect results in the acute infection stage.

Cefoperazone was generally quantifiable for 72 and 84 $\mathrm{h}$ after administration in the initial period and disappeared earlier $(60$ and $72 \mathrm{~h}$ ) in the late period. Kinetic measures such as milk elimination half-life $\left(t_{1 / 2 \lambda z}\right)$ were not different between the periods. Instead, PK measures dependent on the total exposure to drug concentrations (AUC, $\mathrm{C}_{\max }$, and MRT) produced different results $(P<$
0.05). This probably means that environmental conditions could influence drug behavior although perhaps not in the elimination phase.

In the initial period, a longer $(P<0.05)$ elimination half-life was observed in HQ $\left(\mathrm{t}_{1 / 2 \lambda z}=6.73 \pm 2.91 \mathrm{~h}\right)$ than in IQ $\left(\mathrm{t}_{1 / 2 \lambda z}=4.25 \pm 1.85 \mathrm{~h}\right.$; Table 1$)$; the same pattern was recorded in the late period, but the difference was not significant because of larger variation. The elimination half-lives in SQ were similar to IQ values in both periods $(P>0.05)$. At the beginning of the study we felt that SQ could be used as control quarters for infected animals; on the contrary, CFP curve profiles and PK values of SQ were nearer to IQ than $\mathrm{HQ}$, so they were considered as a separate group.

Table 2. Mean $( \pm \mathrm{SD})$ milk pH in healthy (HQ), infected (IQ), and suspected quarters (SQ) before $(0 \mathrm{~h})$ and after treatment $(0.5 \mathrm{~h})$ during the initial and late periods ${ }^{1}$

\begin{tabular}{|c|c|c|c|c|c|c|}
\hline \multirow[b]{2}{*}{ Time } & \multicolumn{2}{|l|}{ HQ } & \multicolumn{2}{|c|}{ IQ } & \multicolumn{2}{|c|}{ SQ } \\
\hline & Mean & $\pm \mathrm{SD}$ & Mean & $\pm \mathrm{SD}$ & Mean & $\pm \mathrm{SD}$ \\
\hline Initial period & \multicolumn{2}{|c|}{$(\mathrm{n}=12)$} & \multicolumn{2}{|c|}{$(\mathrm{n}=8)$} & \multicolumn{2}{|c|}{$(\mathrm{n}=3)$} \\
\hline $0 \mathrm{~h}(\mathrm{t} 0)$ & 6.76 & 0.18 & 6.92 & 0.12 & 6.90 & 0.14 \\
\hline $0.5 \mathrm{~h}$ & $6.71^{*(\mathrm{IQ})}$ & 0.06 & $6.86^{*(\mathrm{HQ})}$ & 0.10 & 6.83 & 0.11 \\
\hline Late period & \multicolumn{2}{|c|}{$(\mathrm{n}=11)$} & \multicolumn{2}{|c|}{$(\mathrm{n}=10)$} & \multicolumn{2}{|c|}{$(\mathrm{n}=2)$} \\
\hline $0 \mathrm{~h}(\mathrm{t} 0)$ & $6.89 \S, *(\mathrm{IQ})$ & 0.02 & $7.04 \S *$ (HQ; & 0.04 & $6.86^{*(\mathrm{IQ})}$ & 0.21 \\
\hline $0.5 \mathrm{~h}$ & $6.76 \S^{*} *(\mathrm{IQ} ; \mathrm{SQ})$ & 0.01 & $6.91^{*,} \S^{(\mathrm{HQ})}$ & 0.03 & $6.86^{*(\mathrm{HQ}}$ & 0.11 \\
\hline
\end{tabular}

${ }^{1}$ Initial and late periods $=$ first (September) and second (October) periods of treatment.

$\S P<0.05$, difference statistically significant between t0 and posttreatment ( $t$-test Welch correction).

${ }^{*} P<0.05$, difference statistically significant between groups (ANOVA); letters in parentheses show groups. 
Table 3. Mean $( \pm \mathrm{SD})$ serum concentrations $(\mu \mathrm{g} / \mathrm{mL})$ of cefoperazone in healthy $(\mathrm{H})$ and infected $(\mathrm{I})$ animals

\begin{tabular}{lcccccc}
\hline & \multicolumn{2}{c}{ Group H $(\mathrm{n}=3)$} & & \multicolumn{2}{c}{ Group I $(\mathrm{n}=3)$} \\
\cline { 2 - 3 } \cline { 5 - 6 } Time $(\mathrm{h})$ & Mean & $\pm \mathrm{SD}$ & & Mean & $\pm \mathrm{SD}$ \\
\hline 0.5 & 0.034 & 0.005 & & 0.051 & 0.008 \\
1 & 0.026 & 0.005 & & 0.056 & 0.027 \\
2 & 0.028 & 0.009 & & 0.058 & 0.006 \\
4 & 0.020 & 0.006 & & 0.102 & 0.079 \\
8 & ND $^{1}$ & - & & 0.045 & 0.025 \\
12 & ND & - & & 0.047 & - \\
24 & ND & - & & 0.025 & - \\
36 & ND & - & & ND & - \\
48 & ND & - & & ND & - \\
\hline
\end{tabular}

${ }^{1} \mathrm{ND}=$ not detected; below limit of detection $=0.002 \mu \mathrm{g} / \mathrm{mL}$.

Some evidence suggests that cows with low milk production eliminate IMM drugs more slowly than cows with higher production (Gehring and Smith, 2006). In the present study, milk production and drug elimination after IMM administration could not be correlated.

Drug serum concentrations were low and close to the lower LOQ $(0.01 \mu \mathrm{g} / \mathrm{mL}$; Table 3$)$. In IQ cows, serum CFP concentrations were more persistent and in 1 subject the drug was still quantifiable at $24 \mathrm{~h}$ after administration. The relationship between drug concentrations attained in serum and in milk is dependent on the drug's solubility in lipid, its ionization, and protein binding rates. Drug diffusion from milk to serum is controlled by milk $\mathrm{pH}$ and drug $\mathrm{p} K_{\mathrm{a}}$ (Gehring and Smith, 2006). An acidic drug such as CFP $\left(\mathrm{p} K_{\mathrm{a}}=2.62\right)$, when dissolved in normal milk ( $\mathrm{pH}$ ranging from 6.5 to 6.8 ), should appear mostly in an ionized form and only partially in the un-ionized form - the form able to reach the bloodstream. The differences observed in milk $\mathrm{pH}$ between HQ and IQ was about +0.15 (Table 2): this should render the drug more ionized and consequently its diffusion in the bloodstream should be lower in IQ than in HQ, in opposition to what we observed. We can theorize that the real mechanism responsible for the slightly higher absorption in IQ animals is the chronic alteration of mammary membrane due to subclinical infections. This suggests slower drug elimination from milk in IQ animals that can be explained by a deeper tissue penetration of drug due to disruption of epithelial cell junctions (Gehring and Smith, 2006).

A shorter elimination half-life in IQ should mean a shorter time in which microorganisms are exposed to drug activity and, therefore, lowered efficacy of CFP. Conversely, considering drug concentrations and the calculation of the appropriate PK/PD measures, the $t>\mathrm{MIC}$ was slightly longer in IQ than in $\mathrm{HQ}(65 \mathrm{~h}$ vs. $58, P>0.05$, and 45 vs. $38 \mathrm{~h}, P<0.05$, in initial and late periods, respectively). This could mean that in IQ, the microorganisms are exposed to drug activity for a prolonged time and CFP efficacy should be increased. For gram-positive bacteria, serum drug concentrations should be above the MIC for at least half the dosing interval (Wagner and Erskine, 2006). The $\mathrm{MIC}_{90}$ value of CFP for Staph. aureus field strains was quite low $(0.64 \mu \mathrm{g} / \mathrm{mL})$ and considering that CFP was administered once, it could be that the drug was able to optimize its efficacy due to the maintenance of concentrations in milk higher than MIC for a long period. At the end of the study, the IQ animals were monitored for health conditions and degree of infection. The results were negative; that is, no Staph. aureus strains were isolated in milk samples collected from IQ animals, thus confirming the efficacy of CFP. However, the standard procedure for MIC determination, used in the present study, is in Mueller-Hinton broth and not in milk. Constable and Morin (2003) reported that the presence of milk during in vitro MIC determination could markedly decrease the activity of antibiotics, mainly because of drug protein or lipid binding or because of the difference in $\mathrm{pH}$ between Mueller-Hinton broth and milk. Thus, it would be interesting to use milk, particularly milk collected from IQ, which would most likely represent the best test medium.

\section{CONCLUSIONS}

The CFP sodium product administered singularly IMM in every quarter at the maximum dose approved of $300 \mathrm{mg}$ of CFP per quarter did not cause any adverse effects and was well tolerated. The $\mathrm{MIC}_{90}$ value of CFP for Staph. aureus field strains was low $(0.64 \mu \mathrm{g} / \mathrm{mL})$. A single IMM administration of CFP in $\mathrm{HQ}$ and IQ animals showed a longer $t>$ MIC in infected quarters (45 $\mathrm{h}$ in October, $P<0.05)$, meaning that Staph. aureus strains could be exposed to antibiotic activity for a longer time in IQ animals. At the end of our study, all the IQ animals were negative for Staph. aureus, confirming the validity of dosage scheme adopted.

\section{ACKNOWLEDGMENT}

The authors thank the Azienda Agricola Groppelli (Bagnolo Cremasco, Lodi, Italy) for the assistance provided.

\section{REFERENCES}

Barkema, H. W., Y. H. Schukken, and R. N. Zadoks. 2006. Invited Review: the role of cow, pathogen, and treatment regimen in the therapeutic success of bovine Staphylococcus aureus mastitis. J. Dairy Sci. 89:1877-1895.

Barragry, T. B. 1994a. Beta-lactam antibiotics. Pages 221-240 in Veterinary Drug Therapy. Lea \& Febiger, Philadelphia, PA.

Barragry, T. B. 1994b. Bovine mastitis. Pages 655-688 in Veterinary Drug Therapy. Lea \& Fabiger, Philadelphia, PA. 
Constable, P. D., and D. E. Morin. 2003. Treatment of clinical mastitis using antimicrobial susceptibility profiles for treatment decisions. Vet. Clin. North Am. Food Anim. 19:139-155.

Gehring, R., and G. W. Smith. 2006. An overview of factors affecting the disposition of intramammary preparations used to treat bovine mastitis. J. vet. Pharmacol. Ther. 29:237-241.

Gibaldi, M., and D. Perrier. 1982. Pharmacokinetics. Marcel Dekker Inc., New York, NY.

National Mastitis Council. 1999. Laboratory Handbook on Bovine Mastitis. Revised. National Mastitis Council Inc., Madison, WI.

McKellar, Q. A., S. F. Sanchez Bruni, and D. G. Jones. 2004 Pharmacokinetic/pharmacodynamic relationships of antimicrobial drugs used in veterinary medicine. J. Vet. Pharmacol. Ther. $27: 503-514$.

NCCLS (National Committee for Clinical Laboratory Standards). 2002. Performance Standards for Antimicrobial Disk and Dilution
Susceptibility Tests for Bacteria Isolated from Animals; Approved Standard. 2nd ed. Document M31-A2. NCCLS, Wayne, PA.

Prescott, J. F. 2006. Beta-lactam antibiotics: Cephalosporins. Pages 121-157 in Antimicrobial Therapy in Veterinary Medicine. 4th ed. S. Giguere, J. F. Prescott, J. D. Baggot, R. D. Walker, P. M. Dowling, ed. Blackwell Publishing, Ames, IA.

Sørensen, L. K., and L. K. Snor. 2000. Determination of cephalosporins in raw bovine milk by high-performance liquid chromatography. J. Chromatogr. A 882:145-151.

Wagner, S., and R. Erskine. 2006. Antimicrobial drug use in bovine mastitis. Pages 507-517 in Antimicrobial Therapy in Veterinary Medicine. 4th ed. S. Giguere, J. F. Prescott, J. D. Baggot, R. D. Walker, P. M. Dowling, ed. Blackwell Publishing, Ames, IA. 